\title{
PELLET INJECTOR RESEARCH AT ORNL
}

D. D. Schuresko, S. L. Milora, S. K. Combs, C. A. Foster, P. W. Fisher,

B. E. Argo, G. C. Barber, C. R. Foust, F. E. Gethers, M. J. Gouge, H H. Haselton, J. E. Moeller, N. S. Ponte, D. W. Simmons, ard J. H. Whitsún

Oak Ridge National Laboratory, ${ }^{*}$ Oak Ridge, Tennressee, 37831, U.S. A.

Several advanced plasma fueling systems are under development at the Oak Ridge National Laboratory (ORNL) for present and future magnetic confinement devices. These include multishot and repeating pneumatic pellet injectors, centrifuge accelerators, electrothermal guns, a Tritium Proof-ofPrinciple experiment, and an uitrahigh velocity mass ablation driven accelerator. A new eight-shot pneumatic injector capable of delivering $3.0 \mathrm{~mm}$, $3.5 \mathrm{~mm}$, and $4.0 \mathrm{~mm}$ diameter pellets at speeds up to $1500 \mathrm{~m} / \mathrm{s}$ into a singie discharge has been commissioned recently on the Tokamak Fusion Test Reactor. The so-called Deuterium Pellet Injector (DPI) is a prototype of a Tritium Pellet Injector (TPI) scheduled for use on TFTR in 1990. Construction of the TPI will be preceded by a test of tritium pellet fabrication and acceleration using a $4 \mathrm{~mm}$ bore "pipe gun" apparatus. A new repeating pneumatic pellet injector capable of $2.7 \mathrm{~mm}, 4 \mathrm{~mm}$, and $6 \mathrm{~mm}$ operation is being installed on the Joint European Torus to be used in ORNL/JET collaborative pellet injection studies. A $1.5 \mathrm{~m}$ centrifuge injector is being developed for application on the Tore Supra experiment in 1988. The new device, which is a $50 \%$ upgrade of the prototype centrifuge used on D-III, features a pellet feed mechanism capable of producing variable-size pellets $(1.5-3.0 \mathrm{~mm}$ diameter $)$ optimally shaped to survive acceleration stresses. Accelerating pellets to velocities in excess of $2 \mathrm{~km} / \mathrm{s}$ is being pursued through two new development undertakings. A hydrogen plasma electrothermal gun is operational at $2 \mathrm{~km} / \mathrm{s}$ with $10 \mathrm{mg}$ hydrogen pellets; this facility has recently been equipped with a pulsed power supply capable of delivering $1.7 \mathrm{~kJ}$ millisecond pulses to low impedance arc loads. A unique ultronigh velocity concept that utilizes an intense electron beam to generate thrust by partially ablating a solid hydrogen pellet is also under development. An $0.5 \mathrm{~m}$ long prototype launcher operating at $30 \mathrm{kV}, 30$ amperes is scheduled for testing in August 1988.

\section{Introduction}

Pellet injection has produced dramatic improvements in tokamak plasma performance in several recent and ongoing experiments ${ }^{1}$, including operation at nigher densities, improved energy confinement, reduced impurity levels, and profile tailoring for auxiliary heating. Pellet injector development to support the needs of present day large tokamaks and future devices is being actively pursued at ORNL. The upcoming fusion experiments will require $2-6 \mathrm{~mm}$ pellets (hydrogen, deuterium, and tritium), produced at 5-10 per second repetition rates for periods rangi.ig from several seconds to steady-state, at maximum attainable speeds, perhaps in excess of $5-10 \mathrm{~km} / \mathrm{s}$.

*Research sponsored by the Office of Fusion Energy, U. S. Department of Energy, under Contract No. DE-AC05-840R21400 with Martin Marietta Energy Systems, Inc.

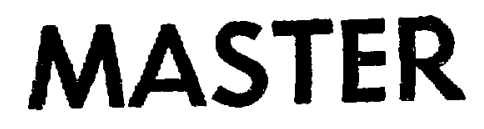




\section{Repetitive Pellet Injector Technology at $1.2 \mathrm{~km} / \mathrm{s}$ Speeds}

Both single-barrel repeating pneumatic ${ }^{2}$ and multiple-barrel discrete shot pellet injectors which can deliver $2.6 \mathrm{~mm}$ hydrogen and deuterium pellets at 1 $1.6 \mathrm{~km}$ /s speeds have been used in pellet injection experiments on the Tokamak Fusion Test Reactor. A versatile pellet injection system, consisting of three single-barrel repeating pneumatic pellet injectors mounted in one common vacuum enclosure, is presently being installed on the Joint European Torus. Individual extruders provide solid hydrogen to each gun assembly; reciprocating solenoid-driven breech tubes repetitively cut and chamber pellets. The injectors deliver $2.7 \mathrm{~mm}, 4.0 \mathrm{~mm}$, and $6.0 \mathrm{~mm}$ size pellets at $5 \mathrm{~Hz}$, $2.5 \mathrm{~Hz}$, and $1 \mathrm{~Hz}$ repetition rates, respectively, for periods of several seconds duration; velocities up to $1.5 \mathrm{~km} / \mathrm{s}$ are attainble for deuterium pellets at $100 \mathrm{bar}$ propellant supply pressures (hydrogen).

A mechanical accelerator which will feature $1.5-3.0 \mathrm{~mm}$ pellets at $1-1.5 \mathrm{~km} / \mathrm{s}$ speeds is being developed for use on Tore Supra in 1988. This injector will utilize a novel pellet forming technique capable of generating sequences of pellets for periods of 10-30 seconds. The pellet generator functions by punching pellets from a rim of deuterium frozen onto a continuously turning cryogenically cooled wheel. The pellet punch can be translated radially in ward or outward with respect to the edge of the deuterium rim, thus generating pellets of the desired size. The pellets are shaped into rounded tetrahedrons or "tacos" by the punching mechanism, which is the proper shape to minimize acceleration stresses.

\section{High Velocity Pellet Injector Development}

The development of a high velocity pneumatic pellet accelerator, which operates with hydrogen plasma propellant, is aimed at the goal of extending the performance of present day pneumatic pellet injectors into the $2-5 \mathrm{~km} / \mathrm{s}$ range 4 . The prototype accelerator consists of a vortex-stabilized arc discharge plasma generator coupled to the breech tube of a "pipe gun" pneumatic pellet injector5. The arc chamber is designed for arc initiation at 1-4 bar pressures, and is constructed from high temperature materials (tungsten or tantalum cathodes, graphite anode, Macor insulators). Electrical power is supplied to the arc from a 5-stage LC-line/pulse transformer supply which can produce $1 \mathrm{~ms}$ pulses at $5 \mathrm{kA}$ currents in to $0.1 \mathrm{ohm}$ loads. The arc is triggered as hydrogen gas is admitted in to the arc chamber: the ohmic dissipation increases the rate of rise of the gun breech pressure from $30 \mathrm{bar} / \mathrm{ms}$ to greater than $100 \mathrm{bar} / \mathrm{ms}$. Muzzle velocities increase from $1.0 \mathrm{~km} / \mathrm{s}$ to $1.3 \mathrm{~km} / \mathrm{s}$ for $25 \mathrm{mg}$ deuterium pellets, and from $1.3 \mathrm{~km} / \mathrm{s}$ to $2.0 \mathrm{~km} / \mathrm{s}$ for $10 \mathrm{mg}$ hydrogen pellets; these increases represent $5-10 \%$ conversion of electrically dissipated energy to projectile kinetic energy. Muzzle velocity data for four pairs of shots with and without arc initiation are plotted vs the constant base pressure velocity calculated from the gun and pellet parameters and the maximum breech pressure in Fig. 1. Also shown are data for the repeating pneumatic injector adapted from Figs. 3 and 7 of ref. 1 , and idealized gun theory performance curves for hydrogen gas at $293 \mathrm{~K}$ and $2000 \mathrm{~K}$. It is aprarant from the comparison between these data that the arc heating results in increased 
propellant sound velocities, and therefore in higher susiained pellet base pressures over the acceleration interval.

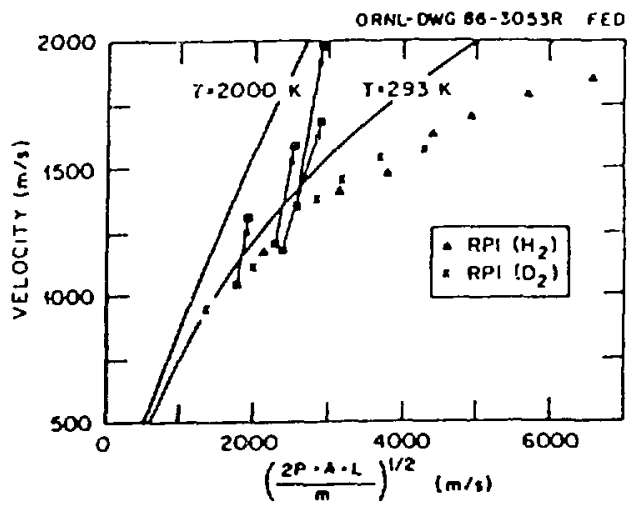

Fig 1. Electrothermal gun performance.

An ablation-driven pellet launcher, powered by an intense electron beam, as is conceptually shown in Fig. 2, is the effort being pursued at ORNL with the aim of attaining pellet velocities in excess of $5-10 \mathrm{~km} / \mathrm{s}$. Composite sticks of hydrogen propellant with deuterium pellet loads are continuously loaded in to a guide rail configuration. The rear surface of these pellets is ablated by a $30 \mathrm{~A}$ beam of $30 \mathrm{kV}$ electrons generated in an e-beam source designed for high quality electron optics. External magnets provide a solenoidal magnetic field to compress and confine the e-beam. First order modelling of the accleration. using the neutral shielding model to calculate the e-beam attenuation in the ablatant, coupled to the rocket equation and to power and mass balances at the pellet/ablatant interface, indicates that ablating $1.6 \mathrm{~cm}$ long propellant sticks should propel $4 \mathrm{~mm}$ deuterium payloads to $14 \mathrm{~km} / \mathrm{s}$. A test of prototype accelerator is scheduled for August 1988.

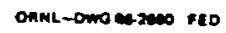

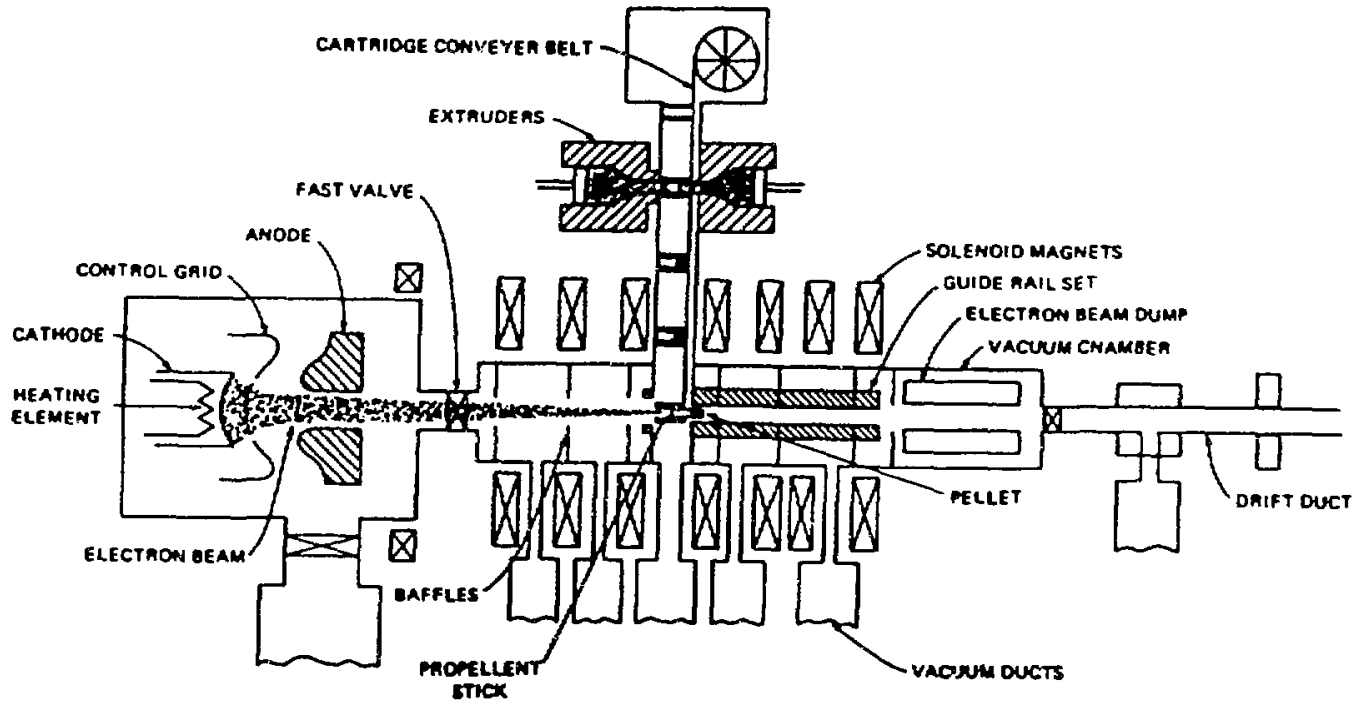

Fig 2. e-beam accelerator concept. 


\section{The Tritium Proof-of-Principle (TPOP) Experiment}

The Tritium Proof-of-Principle (TPOP) experiment is being assembled at ORNL for testing with tritium at Los Alamos National Laboratory's Tritium Systems Test Assembly later this year. TPOP is a single-shot "pipe gun" injector, similar to the unit presently in use in the high velocity development work. With the exception of the high pressure propellant valve stem tip, which is Vespel, the gun is all metal construction, thus insuring tritium compatibility. The gun and pellet injection line are to be located in a glove box, which also house all necessary tritium handling equipment. The system is designed to accommodate enough tritium for one day of operation at TSTA. Helium-3 will be cryogenically removed from the tritium to prevent blocking of the cryopumping action in the gun by non-condensible gas during pellet formation 6 . During operation. a pellet size aliquot of tritium will be metered into the barrel and frozen. The gun and glove box system has been designed to accommodate several types of fast valves and velocity booster concepts. Tritiated gas mixtures produced in the system will be removed and processed by an external vacuum system which is part of the TSTA facility.

\section{References}

1. Collected papers from the International Pellet Fueling Workshop, LaJolla, California, Oct. 30-Nov. 3, 1985. ORNL Conf-8510266.

2. S. K. Combs et al., Rev. Sci. Instrum., 56(6), 1173 (1985).

3. S. K. Combs et al., Rev. Sci. Instrum., to be published (1987).

4. D. D. Schuresko et al., J. Vac. Sci. Tech., to be published (1987).

5. S. K. Combs et al., Rev. Sci. Instrum., 57, 2636(1986)

6. P. C. Souers, Cryogenic Hydrogen Data Pertinent to Magnetic Fusion Energy, UCRL-52628(1979).

\section{DISCLAIMER}

\footnotetext{
This report was prepared as an account of work sponsored by an agency of the United States Government. Neither the United States Government nor any agency thereof, nor any of their employees, makes any warranty, express or implied, or assumes any legal liability or responsibility for the accuracy, completeness, or usefulness of any information, apparatus, product, or process disclosed, or represents that its use would not infringe privately owned rights. Reference herein to uny specific commercial pt: - duct, process, or service by trade name, trademark, manufacturer, or otherwise does not necessarily constitute or imply its endorsement, recommendation, or favoring by the United States Government or any agency thereof. The views and opinions of authors expressed herein do not secessarily state or reflect those of the United States Government or any agency thereof.
} 